\title{
Sequelae of Thallium Poisoning: Clinical and Neurophysiological Follow-Up
}

\author{
J. Kalita U.K. Misra \\ Department of Neurology, Sanjay Gandhi Post Graduate Institute of Medical Sciences, Lucknow, India
}

Dear Sir,

Thallium is a heavy metal and is used as rodenticide, in the manufacture of optical lenses, semiconductors, low temperature thermometer, switching devices, green firework, imitation jewelry, chemical catalyst and as an isotope in nuclear scan $[1,2]$. Industrial and suicidal thallium poisoning in recent years is rare due to unavailability and strict regulation; but still it is used as a homicidal agent, as thallium salts are colorless, odorless and tasteless. Acute thallium poisoning is characterized by multisystem involvement, and neurological manifestations include severe paresthesia, peripheral neuropathy, ptosis, tremor, encephalopathy and cerebellar symptoms [36]. Subacute poisoning manifests itself slowly with alopecia and peripheral neuropathy. Chronic poisoning manifests itself with extrapyramidal features, especially parkinsonian tremor and choreoathetosis [3]. Studies on long-term follow-up of acute thallium poisoning are few, and persistent cognitive, visual and peripheral neuropathy have been reported in some patients $[7,8]$. There is no study evaluating delayed sequelae of acute thallium poisoning employing multimodality evoked potentials. We have reported acute complications of a patient with homicidal thallium poisoning [4]. In this communication we report clinical and neurophysiological sequelae of the same patient 3 years later.

\section{Case Report}

A 42-year-old male presented with symptoms of peripheral neuropathy, diarrhea, vomiting, and renal and hepatic dysfunction following homicidal thallium poisoning. Gradually the patient became drowsy and developed ptosis, glossitis, stomatitis, alopecia, Mees lines, head tremor and nystagmus. His blood thallium level was $40,980 \mu \mathrm{g} / \mathrm{ml}$ and urine $608 \mu \mathrm{g} / \mathrm{ml}$. He was treated with hemodialysis, potassium, laxatives and high-dose multivitamins. Gradually his sensorium improved, and ptosis and head tremor disappeared, but he developed grade 3 quadriplegia with glove and stocking sensory loss. Biceps, triceps and knee reflexes were normal, and ankle reflexes were absent bilaterally. His Mini-Mental State Examination (MMSE) score was 22, and the patient had postural hypotension. At the 3-month follow-up, the patient was completely bald (fig. 1a) and dependent for activities of daily living. He had masking of face, abulia, gaze evoked nystagmus and unsteady gait. Vision was $6 / 60$ bilaterally and the fundus normal. Muscle power was grade 4 at the knee and grade 3 at the ankle, with loss of ankle reflex. The touch and pinprick sensations were diminished bilaterally below the ankle. His biochemical tests for liver and kidney functions were normalized. By 6 months he was able to walk independently with mild unsteadiness but was unable to resume duty due to poor vision. His symptoms related to autonomic dysfunction such as postural giddiness, dryness of mouth and eyes, and reduced sweating improved by 1 year but the decreased libido persisted even at the 3-year follow-up. At the 3-year follow-up he was independent for activity of daily living, and his MMSE score was 30. He had mild extrapyramidal signs (masking, positive
Mearson's sign, broken saccades and pursuit eye movements, and loss of associated movement during walking) and cerebellar signs (gaze evoked nystagmus, defective tandem walking). The visual impairment remained the same (6/60). Cranial nerves, power and sensations were normal. Detailed autonomic function tests revealed mild abnormality. There was a $10-\mathrm{mm}$ drop of systolic blood pressure on standing, an expiration-inspiration heart rate variation of $10(n>15)$, an expiration-inspiration R-R ratio of $1.1(\mathrm{n}>1.5)$ and a blood pressure rise on cold immersion of $8 / 6 \mathrm{~mm} \mathrm{Hg}$. His sural nerve biopsy performed on the 40th day revealed loss of axons, active axonal degradation, and increased endoneurial collagen and inflammatory cell infiltration. Kulchitsky Pal stain showed demyelination.

\section{Neurophysiological Evaluation}

Nerve conduction study revealed progressive deterioration till month 3 , which became normalized at 3 years (fig. 1b). Initial unrecordable peroneal $F$ response became normal at the 3-year follow-up, although peroneal $\mathrm{F}$ persistence was only $10 \%$. The details of the nerve conduction studies are summarized in table 1. P100 latency of visual evoked potential (VEP) and tibial somatosensory conduction time were prolonged at 1 month and remained so even at 3 years (fig. $1 \mathrm{c}, \mathrm{d}$ ), but the central motor conduction time to the tibialis anterior was normal. Cognitive evoked potential using the auditory paradigm at the 3year follow-up revealed normal P300 latency $(272 \mathrm{~ms})$ and amplitude $(23.5 \mu \mathrm{V})$.

\section{KARGER}

Fax +4161306 1234 E-Mail karger@karger.ch www.karger.com
(C) 2006 S. Karger AG, Base $0014-3022 / 06 / 0564-0253 \$ 23.50 / 0$

Accessible online at: www.karger.com/ene
Dr. J. Kalita

Department of Neurology, Sanjay Gandhi PGIMS

Rae Bareily Road

Lucknow 226014 (India)

Fax +91 522266 8017, E-Mail jkalita@sgpgi.ac.in 


\section{Discussion}

Our patient with acute thallium poisoning recovered completely from neuropathy both clinically and neurophysiologically but had no improvement in visual functions at the 3-year follow-up. The extrapyramidal, cerebellar and autonomic dysfunctions improved significantly, and he had subclinical posterior column dysfunction as evidenced by prolonged tibial somatosensory evoked potential (SEP). There is paucity of long-term follow-up reports on comprehensive neurophysiological evaluation on thallium poisoning. A study on sequential nerve conductions reported persistently unrecordable plantar and posterior tibial nerve conduction till 2 years and sural nerve conduction up to 1 year, although he improved clinically [9]. Nerve conductions and sural nerve biopsy in this patient were consistent with axonal neuropathy, which is similar to our patient. However, we had not done plantar and posterior tibial nerve conduction studies, but our patient had normal sural conductions, and his unrecordable peroneal nerve conduction became normal at 3 years. This may be due to difference in amount of thallium exposure or individual susceptibility. Visual loss in thallium poisoning has been attributed to optic neuritis, maculopapular bundle involvement, iridocylitis and cataract. According to Böhringer [10] severe lesions of the optic nerve are observed in approximately $25 \%$ of patients suffering from a single attack of acute thallium poisoning and $100 \%$ after repeated small dose. In a study on 70 patients, 9 developed optic neuritis. Blindness did not improve in 2, who eventually died, and in 1 patient there was permanent destruction of the central bundle with 0.05 visual acuity [7]. Although visual impairment is a common symptom and sequela of thallium poisoning, there is paucity of reports on VEP. In one study impaired vision and prolonged P100 latency on VEP have been reported and attributed to optic neuritis. Vision at week 6 became normal in the left eye and 6/12 in the right, but follow-up VEP was not done [8]. Visual impairment and VEP in our patient did not improve even at 3 years, which may be due to severe irreversible toxic optic neuropathy. Reduction of P100 amplitude and prolongation of latency suggest an axonal nature of optic neuropathy with secondary demyelination. Plasma exchange may not be helpful in improving visual impairment.

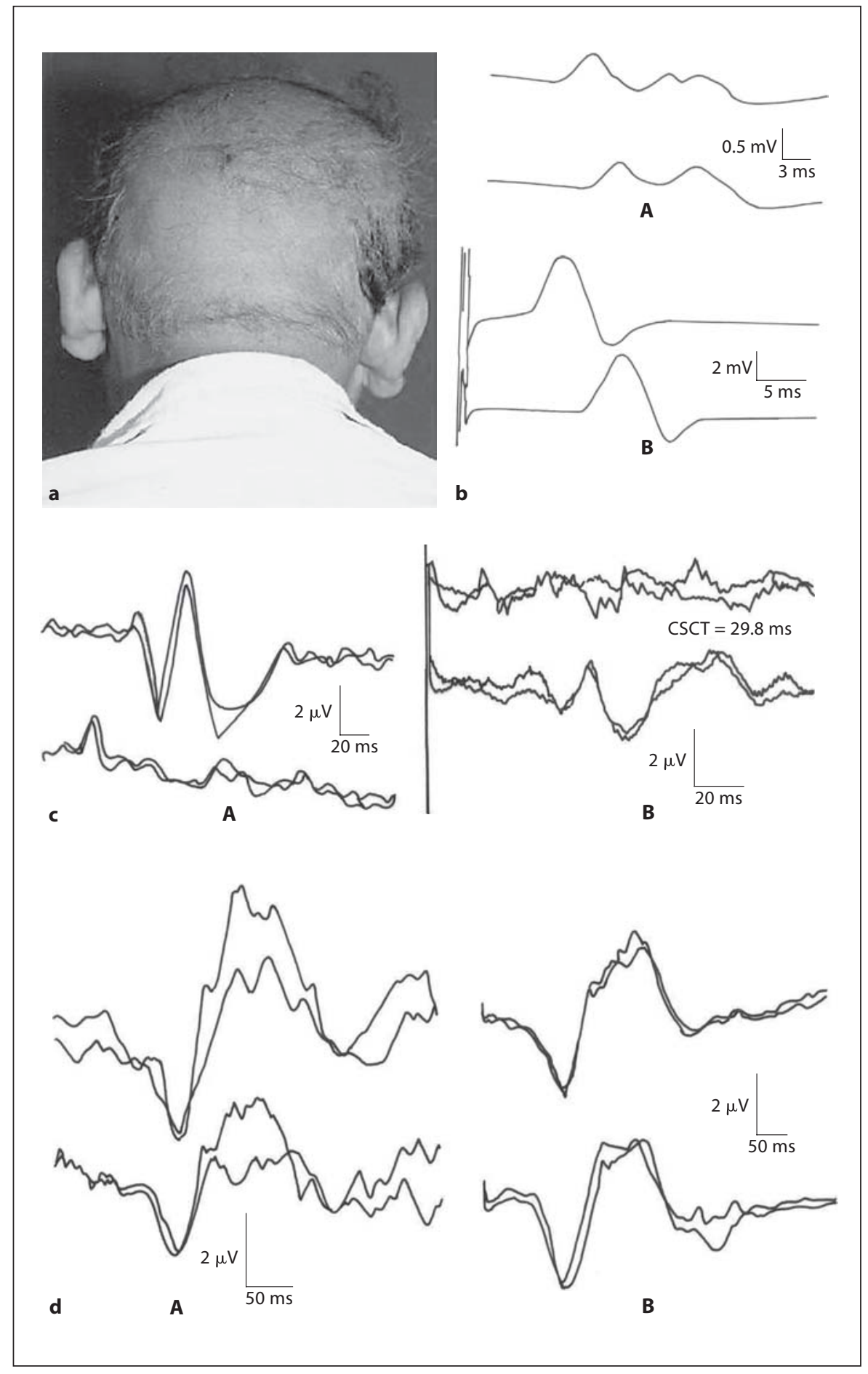

Fig. 1. a Alopecia in a patient with thallium poisoning on day 30. b Peroneal nerve conduction study showing normal conduction velocity with reduced compound muscle action potential $(0.5 \mathrm{mV})$ on day 5 of illness $(\mathbf{A})$, which became normal $(4 \mathrm{mV})$ at the 3 -year follow-up (B). c Tibial central sensory conduction time (CSCT) was markedly prolonged (43 $\mathrm{ms}$ ) at 3 months (A) but improved at the 3-year follow-up (B), although remaining prolonged $(29.8 \mathrm{~ms})$. d VEP study of right eye revealed prolonged P100 latency (126 ms) both at the 3-month (A) and 3-year follow-up (B), which correlated with lack of clinical improvement in vision. 
Table 1. Nerve conduction and evoked potential studies in a patient with acute thallium poisoning

\begin{tabular}{lllll}
\hline & 5 th day & 15th day $(\mathrm{R} / \mathrm{L})$ & 3 months $(\mathrm{R} / \mathrm{L})$ & 3 years $(\mathrm{R} / \mathrm{L})$ \\
\hline $\begin{array}{l}\text { Motor NCV, m/s } \\
\quad \text { Peroneal }\end{array}$ & $53.2[0.5]$ & $\mathrm{NR}$ & $55.9[0.44]$ & $52.6[4]$ \\
$\quad$ Median & $58.9[5.5]$ & $57.6[4]$ & $51.1[4.4]$ & $57.1[8.5]$ \\
$\quad$ Ulnar & $58.1[6]$ & $56.2[5.1]$ & $53.5[6.5]$ & $61[9.5]$ \\
SNCV, m/s & & & \\
$\quad$ Sural & $56.8(16.4)$ & $50(17.8)$ & $47.5(17.2)$ & $52.3(33.1)$ \\
$\quad$ Median & $54(48)$ & $55.7(30)$ & $48.3(19.6)$ & $49(17.7)$ \\
$\quad$ Ulnar & $54.7(35)$ & $54.3(19.6)$ & $48.2(12.6)$ & $48.8(17.1)$ \\
F latency, ms & & & & \\
$\quad$ Median & 31.2 & 31.6 & 31 & 25.9 \\
$\quad$ Ulnar & 26.8 & 26 & 27 & 42 \\
$\quad$ Peroneal & NR & NR & NR & $126(2.56) / 120(3.28)$ \\
VEP R/L P100 latency, ms & ND & ND & $126(2) / 126(2)$ & $11.2 / 11.2$ \\
CMCT-TA, ms & ND & ND & $10.8 / 11$ & $29.8 / 28$ \\
Tibial CSCT, ms & ND & ND & $43 / 40$ & $272(23.5)$ \\
P300 latency, ms & ND & ND & ND & \\
\hline
\end{tabular}

The figures in square brackets indicate amplitude in millivolts and those in parentheses represent amplitude in microvolts. $\mathrm{NCV}=$ Nerve conduction velocity; $\mathrm{SNCV}=$ sensory nerve conduction velocity; $\mathrm{VEP}=$ visual evoked potential; CSCT = central sensory conduction time; CMCT-TA = central motor conduction time to tibialis anterior; $\mathrm{NR}=$ not recordable; $\mathrm{ND}=$ not done; $\mathrm{R}=$ right; $\mathrm{L}=$ left.

In the acute stage of thallium poisoning, various neuropsychiatric disorders such as agitation, depression, apathy, paranoia, confabulation and psychosis have been described [7, 11-13]. In long-term follow-up impairment of concentration, memory and excessive emotional outburst have been reported $[12,14]$. However, none of these studies correlated cognitive impairment with cognitive evoked potential. Our patient had apathy and depression at presentation and a low MMSE score at 3 months, which improved later. His cognitive evoked potential at 3 months could not be assessed, but follow-up study revealed normal P300 latency and amplitude, which correlated with the clinical improvement. Marked cerebellar, extrapyramidal and autonomic dysfunctions present at 1 month of illness improved significantly, but subtle residual deficits persisted even at 3 years of follow-up. There are no clinical reports of acute thallium poisoning and its sequelae. Autopsy studies, however, showed cerebellar edema, loss of Purkinje cells, and involvement of dorsal root ganglia, basal ganglia and posterior column [3]. The subclinical SEP abnormality in our patient may be due to posterior column involvement.
Clinico-neurophysiological evaluation at 3 years of this patient with acute thallium poisoning revealed complete recovery from peripheral neuropathy and cognitive impairment, mild residual deficits in extrapyramidal, cerebellar and autonomic function and no improvement in visual impairment. SEP may be helpful in evaluating subclinical posterior column abnormality.

\section{Acknowledgment}

We are thankful to Mr. Rakesh Kumar Nigam for technical help.

\section{References}

1 Lynch GR, Lond MB, Scovell JMS: The toxicology of thallium. Lancet 1930;ii:13401344.

2 Saddique A, Peterson CD: Thallium poisoning - a review. Vet Hum Toxicol 1983;25:1622.

3 PrickJJG: Thallium poisoning; in Vinken PJ, Bruyn GW (eds): Handbook of Clinical Neurology. Amsterdam, North Holland Publishing, 1979, vol 36, pp 239-279.

4 Misra UK, Kalita J, Yadav RK, Ranjan P: Thallium poisoning: emphasis on early diagnosis and response to haemodialysis. Postgrad Med J 2003;79:103-105.
5 Hughes MN, Man WK, Whaler BC: The toxicity of thallium(I) to cardiac and skeletal muscle. Clin Biol Interact 1978;28:85-97.

6 Grisham CM, Cuptra RK, Barnett RE, Mildvan AS: Thallium-205 nuclear relation and kinetic studies of sodium and potassium ionactivated triphosphatase. J Biol Chem 1974; 249:6738-6744.

7 Moeschilin S: Thallium poisoning. Clin Toxicol 1980;17:133-146.

8 Moore D, House I, Dixon A: Thallium poisoning: diagnosis may be elusive but alopecia is the clue. BMJ 1993;306:1527-1529.

9 Dumitru D, Kalantri A: Electrophysiologic investigation of thallium poisoning. Muscle Nerve 1990;13:433-437.

10 Böhringer HR, cited in Moeschilin S: Thallium poisoning. Clin Toxicol 1980;17:133146.

11 Viri AA, Cremers HMHG, Lustermans FA: Successful recovery of a patient with thallium poisoning. Neth J Med 1995;47:121126.

12 Steinberg HJ: Accidental thallium poisoning. South Med J 1961;54:6-9.

13 Bank WJ, Pleasure DE, Suzuki K, Nigro M, Katz R: Thallium poisoning. Arch Neurol 1972;26:456-466.

14 McMillan TM, Jacobson RR, Gross M: Neuropsychology of thallium poisoning. J Neurol Neurosurg Psychiatry 1997;63:247-250. 